University of Wollongong

Research Online

Faculty of Engineering and Information

Faculty of Engineering and Information

Sciences - Papers: Part B

Sciences

2019

Novel hybrid FRP tubular columns with large deformation capacity: Concept and behaviour

Tao Yu

University of Wollongong, taoy@uow.edu.au

Hongchao Zhao

University of Wollongong, hz449@uowmail.edu.au

Ting X. Ren

University of Wollongong, tren@uow.edu.au

Alex M. Remennikov

University of Wollongong, alexrem@uow.edu.au

Follow this and additional works at: https://ro.uow.edu.au/eispapers1

Part of the Engineering Commons, and the Science and Technology Studies Commons

Research Online is the open access institutional repository for the University of Wollongong. For further information contact the UOW Library: research-pubs@uow.edu.au 


\title{
Novel hybrid FRP tubular columns with large deformation capacity: Concept and behaviour
}

\begin{abstract}
Extensive studies have been conducted on the use of fibre-reinforced polymer (FRP) as a confining material in hybrid tubular columns for civil construction, where the design of columns is often controlled by the stiffness and/or strength requirements. By contrast, the capacity of sustaining large deformation without losing structural integrity can be critical in some applications such as the standing supports for underground mines. This paper presents the conceptual development of a novel column form with large deformation capacity. The novel column consists of an outer FRP tube, and an infill made of coarse lumps/aggregates, which can be from coal rejects or other waste/recycled materials, as well as calcium sulfoaluminate (CSA)-based cementitious material with high water content. In addition to its large deformation capacity, the new column allows the extensive, direct and easy use of waste materials and eliminates the need for mixing concrete on site or transporting commercial concrete. This paper also presents the results from a series of compression tests on the new columns as well as two similar column forms. These tests demonstrate the very large deformation capacity of the new column and show that an existing stress-strain model for FRP-confined normal concrete can be used to provide reasonable predictions of the behaviour of the confined infill material in the new column. The potential applications of the new column and the needs for future research are also discussed.

\section{Disciplines}

Engineering | Science and Technology Studies

\section{Publication Details}

Yu, T., Zhao, H., Ren, T. \& Remennikov, A. (2019). Novel hybrid FRP tubular columns with large deformation capacity: Concept and behaviour. Composite Structures, 212 500-512.
\end{abstract}




\section{INTRODUCTION}

Columns are considered to be critical members of many structural systems. Various hybrid/composite columns, in which two or more materials are optimally combined for improved structural performance, have been developed. Typical examples include concretefilled steel tubular (CFST) columns [1-4] and concrete-encased steel columns [5, 6], among others. More recently, the use of fibre-reinforced polymer (FRP) as a confining material has become increasingly popular in civil infrastructure [7, 8]. As a result, a number of novel hybrid columns incorporating an FRP confining tube have been proposed, including concretefilled FRP tubular (CFFT) columns [9, 10] and FRP-concrete-steel double-skin tubular columns (DSTCs) [11-14]. Most of these existing hybrid tubular columns, which were initially proposed for application in civil infrastructure such as buildings and bridges, are characterized by their large stiffness and high strength to satisfy both the serviceability and ultimate limit states. However, in some applications such as the standing supports for underground mines, one of the most critical requirements is the capacity of sustaining large deformation (e.g. $>5 \%$ of the column height) without losing the structural integrity.

Various standing supports have been used in underground mines and they are successful to different extents (Figure 1). Among the existing standing supports, the two most popular forms appear to be: (1) steel tubular members with an infill material (Figures 1a and 1b) [15, 16]; (2) pumpable standing supports (Figures 1c and 1d). The former is similar to CFST 
columns used in civil applications, except that the infill material is often not normal concrete for various reasons. For example, foam concrete with a relatively low strength (e.g. $<10 \mathrm{MPa}$ ) may be used for a reduced weight and thus ease for transportation [17]; the use of coarse aggregate/sand as the infill material has also been explored in some recent studies [18, 19]. Because of the existence of a ductile steel tube, this form of standing supports are able to experience large deformation without collapse; the steel tube also provides confinement to the infill material which may otherwise quickly lose its integrity under loading. Therefore, such standing supports, exemplified by the product Can ${ }^{\circledR}$ support developed by the Burrell Mining, have found wide applications in underground mining [16, 20, 21]. However, under large deformation, the steel tube in such columns suffers from severe local buckling (Figure 1b) which may lead to significant loss in the load capacity. It should also be noted that the confinement from the steel tube, although useful in retaining the integrity of the infill material, is typically not effective in enhancing its strength, as the confining pressure becomes constant after the yielding of steel and can be mostly lost when local buckling occurs. In addition, steel tubular standing supports suffer from their relatively large weight, and are generally unsuitable for applications where coal-cutting machine is used because of the potential risk of gas explosion caused by cutting sparks.

Pumpable standing supports typically consist of a soft fabric bag which is filled on site with various pumpable cementitious materials (e.g. aerated cement, Portland cement, Portland pozzolan cement and ettringite-based cement) [22, 23]. This construction process eliminates potential difficulties associated with the transportation of heavy members to the underground and thus facilitates the wide application of such supports. The load capacity of pumpable supports comes mainly from the infill cementitious materials, which, however, are typically brittle. The external fabric bag normally has only limited stiffness and strength, and thus cannot provide effective constraints/confinement to the infill material. Therefore, pumpable supports generally lose their load capacity quickly after the infill material reaches its strength (Figure 1d).

Against this background, this paper presents the conceptual development of a novel type of compression members, which have a large deformation capacity, and is stiff, strong and yet easy to construct. Results from a series of axial compression tests on the novel compression members are also presented to demonstrate some of their expected advantages.

\section{NOVEL HYBRID FRP TUBULAR COLUMNS}

The novel hybrid FRP tubular columns, developed at the University of Wollongong, consists of an outer tube made of FRP, and an infill made of coarse lumps/aggregates, which can be from coal rejects or other waste materials (e.g. recycled aggregates or recycled concrete lumps), as well as calcium sulfoaluminate (CSA)-based cementitious material with high water content (Figure 2a). In the novel columns, the FRP tube offers mechanical resistance primarily in the hoop direction to confine the infill material, so it does not need to be thick and is thus lightweight and cost-effective. Such a tube may also be replaced by a strong yet soft fabric (e.g. ultra-high-molecular-weight polyethylene) when preferred. The CSA-based cementitious material, referred to also as high-water material/super high-water material [24, 25], can be used with a high water-to-powder ratio to provide the high water content (i.e. up to $95 \%$ by volume) and is thus highly flowable [26, 27].

The novel tubular columns are a variation of CFFTs. Compared with CFFTs, the novel feature of the proposed columns is the direct use of coarse lumps/aggregates, preferably from 
waste materials (e.g. coal rejects and recycled concrete lumps), together with high-water material as the infill material. Therefore, the novel columns are hereafter referred to as LHFFTs, and the infill material are referred to as the LH material. The highly flowable highwater material is able to completely fill the voids between the coarse lumps/aggregates which do not need to be specifically prepared and graded for the columns; the construction process of LHFFTs also does not involve concrete mixing/vibration and associated equipment. The simple change of infill material in LHFFTs leads to a number of advantages: (1) it allows the extensive, direct and easy use of waste materials which take up the majority of the space inside the tubes; (2) it eliminates the need for, and the difficulties associated with, mixing concrete on site or transporting commercial concrete, which is particularly important for some applications (e.g. for underground mines); and (3) it significantly reduces the construction cost. It should also be noted that the use of an FRP confining tube is essential for the proposed columns to have a considerably large load capacity, as the LH material may otherwise have a very low strength (i.e. typically less than $5 \mathrm{MPa}$ ). This is further explained later in this paper using experimental results.

The typical section form of LHFFTs (Figure 2a) consists of a circular FRP tube and both coarse lumps/aggregates (i.e. L) and high-water material (i.e. H), but many different combinations are possible. Whenever preferred, the infill material can be made of high-water material only (Figure 2b), or coarse lumps/aggregates only (Figure 2c); the resulting columns are hereafter referred to as HFFTs and LFFTs, respectively. Compared with LHFFTs, HFFTs involve the use of a much larger amount of CSA-based cementitious material and may have a lower strength due to the lack of coarse lumps/aggregates, but can be an attractive option when the coarse lumps or other aggregates are not locally available or easily accessible. Similarly, LFFTs can be an attractive option for some applications due to the elimination of high-water material, but they are expected to have a much lower initial stiffness than LHFFTs because of the voids between the lumps. Whenever necessary, LHFFTs may also be provided with an additional tube made of plastic or other materials (e.g. Polyvinyl chloride, PVC) to further increase the stiffness/strength (Figure 2d). Figure 2e shows a further varied section form consisting of a rectangular outer tube, two or more inner tubes, with the LH material filled in the inner tubes while the coarse lumps filled between the tubes. Such rectangular columns are expected to have a reasonably large initial stiffness as well as a large deformation capacity, and can be attractive for some applications such as the airtight wall or to replace coal pillar in underground mines.

Direct comparisons can be made between LHFFTs and the two widely used standing supports in underground mines, namely, CFSTs and pumpable supports. Compared with CFSTs, besides the advantages of using an LH infill as discussed above, LHFFTs also benefit from the use of an FRP tube because: (1) it is lightweight due to the high strength-to-weight ratio of FRP; (2) its confinement effectiveness on the infill material is not compromised by buckling as the FRP tube generally consists of fibres in or close to the hoop direction only; and (3) it can be easily cut without suffering from the sparks normally resulted from the cutting of a steel tube. Compared with pumpable supports, the stiff and strong FRP tube in LHFFTs provides effective confinement which is essential for enhanced strength and ductility of the infill material. LHFFTs are thus a much stronger and ductile alternative to existing pumpable supports, as further demonstrated later in this paper using experimental results.

A series of axial compression tests were conducted on LHFFTs to demonstrate the structural concept. In parallel, tests were conducted on corresponding HFFTs and LFFTs for 
comparison. In the subsequent sections, this paper presents the experimental program as well as results from the compression tests.

\section{EXPERIMENTAL PROGRAMME}

\subsection{Test Specimens}

A total of 15 FRP tubular specimens were prepared and tested, comprising nine LHFFT specimens as well as three HFFT specimens and three LFFT specimens. All specimens had a diameter of $150 \mathrm{~mm}$ (inner diameter of the FRP tube) and a height of $300 \mathrm{~mm}$. The nine LHFFT specimens covered three different configurations; three identical specimens were made for each configuration. The only difference between the three configurations was the thickness of the FRP tubes, which were made of one-ply, two-ply and three-ply glass fiber fabrics, respectively. The three HFFT specimens were nominally identical and all contained a two-ply glass FRP (GFRP) tube; the same GFRP tube was also used for the three nominally identical LFFT specimens. For all LHFFT and HFFT specimens, the same high-water material product was used with a water-to-powder ratio of 2.0. For all LHFFT and LFFT specimens, the same batch of aggregates were used. While waste materials (e.g. coal rejects and recycled concrete lumps) are preferred in practice instead of aggregates, the use of aggregates in the test specimens retained the essential mechanism of interaction between the constituents, and was thus capable of demonstrating the effectiveness of the new column form.

The details of all the specimens are summarized in Table 1. Each specimen is given a name for ease of reference, which starts with four or five letters (i.e. HFFT, LFFT or LHFFT) to represent the type of specimens, followed by a number $(1,2$ or 3 ) representing the number of plies of fibre fabrics in the FRP tube. The last Roman number is used to differentiate the three nominally identical specimens of each configuration.

\subsection{Material Properties}

\subsubsection{FRP tube}

All the FRP tubes for the column specimens were prefabricated using E-glass fibre fabrics and epoxy resin via a wet-layup process, with an overlapping zone of $150 \mathrm{~mm}$. The fabrics contained fibres mainly ( $90 \%$ by mass) in the major direction, with the rest of the fibres $(10 \%$ by mass) perpendicular to the major direction. In producing the tubes, the major direction of the fabric was aligned with the hoop direction of the tubes. Each end of the FRP tubes was reinforced with a $30 \mathrm{~mm}$ wide GFRP strip to avoid premature failure near the ends.

Three FRP coupons with a nominal thickness of $0.17 \mathrm{~mm}$ per ply (based on the weight of fibres) were prepared using the same fibre fabrics and were tested under tension in the major direction, in accordance with ASTM D3039/D3039M [28]. These test results showed that the FRP used had an average elastic modulus of $80.5 \mathrm{GPa}$ and an average tensile strength of 1127.6 MPa.

To evaluate the axial compressive properties of the FRP tubes, nine FRP rings were prepared and tested according to GB5350-2005-T [29]. The FRP rings were divided into three groups, which were made of one-ply, two-ply and three-ply fibre fabrics, respectively. Each group included three nominally identical specimens, which each had a height of $60 \mathrm{~mm}$ and were 
cut from the same long FRP tube. Figure 3 shows typical specimens during test. As shown in Figure 3, the one-ply and two-ply rings all experienced significant localized buckling during the tests followed by severe cracking in the epoxy resin matrix. The three-ply rings, however, failed only by the fracture of resin. Figure 4 shows the axial load-shortening curves of the FRP rings, while their peak loads are summarized in Table 2.

\subsubsection{High-water material}

The high-water material was produced in the lab using the commercially available product supplied by China Mining \& Civil New Material Science and Technology Co., Ltd. The product, in the form of powders, consists of two components (Components A and B) which can be mixed together with water to form the high-water material. Component A mainly consists of CSA cement, while component B consists mainly of quick lime and gypsum with some additives [30,31]. For all the specimens in the present study, a water-to-powder ratio of 2.0 was adopted. The initial time of setting of the resulting high-water material was 8 minutes while the final time of setting was 32 minutes, as measured according to ASTM C191-13 [32].

A total of 12 plain cylinders of the high-water material, each with a diameter of $150 \mathrm{~mm}$ and a height of $300 \mathrm{~mm}$, were prepared to obtain the compressive strengths at different ages. All the cylinders were wrapped with a plastic sheet to prevent the loss of moisture before being tested at 1 day, 3 days, 7 days and 28 days, respectively, in accordance with MT/T 420-1995 [33]. The average compressive strengths of these specimens are summarized in Table 3 . In addition, three plain high-water material cylinders were prepared and tested during the period of testing the FRP tubular specimens, and the test results are presented later in this paper.

\subsubsection{LH material}

All LH materials used in the FRP tubular specimens were prepared using the high-water material described above and the same batch of aggregates. The aggregates, with a nominal maximum size of $20 \mathrm{~mm}$, were subjected to sieve analysis in accordance with ASTM C136 / C136M-14 [34]. Figure 5 shows the results of the sieve analysis. In preparing the LHFFT specimens, aggregates were first filled into the FRP tube until they reached the top end of the tube. High-water material was then poured in until the FRP tube is full. The aggregates and the high-water material consumed for each LHFFT specimens were summarized in Table 1.

A total of 12 plain cylinders of the LH material, each with a diameter of $150 \mathrm{~mm}$ and a height of $300 \mathrm{~mm}$, were prepared using standard steel moulds. Again, all the cylinders were wrapped with a plastic sheet before being tested at different ages. The average compressive strengths of these cylinders are summarized in Table 3. In addition, three plain LH material cylinders were prepared and tested during the period of testing the FRP tubular specimens, and the test results are presented later in this paper.

\subsection{Preparation of specimens}

The preparation of LHFFT specimens consisted of the following steps: (1) prefabricating the FRP tubes via a wet-layup process (Figures 6a); (2) fixing the FRP tubes on a wooden frame with a waterproof bottom plate (Figure 6b); (3) filling the aggregates and then the high-water material into the FRP tubes (Figure 6c); (4) covering the specimens with plastic sheets until the test dates; For HFFT and LFFT specimens, a similar preparation process was adopted, except that Step (3) only involved the filling of high-water material or aggregates. 


\subsection{Test set-up and instrumentation}

For each specimen with an FRP tube, six strain gauges with a gauge length of $20 \mathrm{~mm}$ were installed, including four hoop strain gauges and two axial strain gauges, all at the mid-height of the specimen. The layout of strain gauges is shown in Figure 7. In addition, four linear variable displacement transducers (LVDTs) were installed for each FRP tubular specimens to measure the axial deformation. Two of the LVDTs were used to measure the overall axial shortening, while the other two were used to measure the deformation of the $100 \mathrm{~mm}$ midheight region.

The two ends of all FRP tubular specimens were capped with high strength gypsum plaster before test. All compression tests were carried out using an Avery 500-ton compression testing machine with a displacement control rate of $0.6 \mathrm{~mm} / \mathrm{min}$ following ASTM D7012 [35]. All test data, including the strains, loads, and displacements, were recorded simultaneously by a data logger.

\section{EXPERIMENTAL RESULTS AND DISCUSSIONS}

\subsection{General Behaviour}

All the FRP tubular specimens failed by rupture of FRP tube due to hoop tension. Typical specimens after test are shown in Figures 8-9. For all LHFFT specimens, the load kept increasing until explosive rupture of FRP occurred in the hoop direction, except for Specimens LHFFT-1-III and LHFFT-2-I; for these two specimens, localized hoop rupture of FRP occurred during the test, causing a sudden load drop, after which the specimens could continue to take an increasing load until the final explosive rupture of FRP (Figure 10). For all HFFT and LFFT specimens, there were some small load fluctuations during the test (Figures 11 and 12). Because of the large axial deformation experienced by the specimens, numerous cracks (white patches, see Figures 8-9) occurred in the resin matrix of the FRP tube before the final failure. These cracks might have caused the small load fluctuations in the HFFT and LFFT specimens, but did not affect their structural integrity; the load could still keep increasing or nearly constant for these specimens, despite the cracks, until the hoop FRP rupture.

The rupture of FRP tube in LHFFT specimens generally occurred at or near the mid-height of the specimens (Figure 8a). After test, the FRP tube was removed to examine the infill material. It is interesting to note that severe local damage of the infill LH material occurred at approximately the same height of the FRP rupture. Such local damage, however, did not occur in the tested plain LH cylinders (Figure 8b), which generally failed by vertical cracks uniformly distributed over the specimens.

The FRP rupture of HFFT specimens also generally occurred near the mid-height of the specimens, but there was no obvious local damage on the infill high-water material as found after removing the FRP tube (Figure 9a). Instead, several horizontal cracks occurred and the whole specimen deformed to a curved shape with a large axial shortening. It is also worth noting that some water was squeezed out from the high-water material during the test.

For LFFT specimens, the cracks in the resin matrix of FRP occurred much earlier than in their LHFFT counterparts. This is easy to understand as the aggregate infill in the LFFT 
specimens started to take a significant load only after a certain axial shortening of the specimens occurred, due to the voids between the aggregates. Therefore, at the beginning of the test, the FRP tube was the main component that was directly loaded. It was also noted that some of the aggregates were crushed after test (Figure 9b), suggesting that the strength of aggregates may be an important factor for the strength of LFFT specimens.

\subsection{Axial Load-Shortening Behaviour}

The axial load-shortening curves of all LHFFT specimens are shown in Figure 10 in which the curves of the corresponding plain LH cylinders are also plotted for comparison. It is evident that all curves of the LHFFT specimens feature an approximately bilinear shape, and are much higher than the curve of the corresponding plain cylinders.

The key test results are summarized in Table 4 . In this table, $P_{u}$ is the ultimate load of LHFFT specimens from the test, $P_{h w}$ is the average ultimate load from the tests of plain LH cylinders,

$P_{f r p}$ is the average ultimate load from the tests of hollow FRP rings, and $\left(P_{h w}+P_{f r p}\right)$ represents the ultimate load of the LHFFT if the confinement effect of the FRP tube is ignored. The ultimate axial shortening, which is the axial shortening at the rupture of the FRP tube, is denoted by $S_{u}$ and is also given in Table 4 . It is evident from the table that the load capacity of LHFFT specimens is much higher than (up to 3.6 times) the simple sum of those of the infill LH material and the FRP tube, suggesting that the effect of FRP confinement is significant. The ultimate axial shortening of LHFFT specimens is shown to be up to around 8.6\% of their height, and is much larger than (up to 17 times) that corresponding to the peak stress of unconfined LH cylinders (i.e. $S_{l h}$ in Table 4 ).

Figures 10b-c show that when a two- or three-ply FRP tube was used, the three nominally identical specimens possess very similar axial load-shortening curves, with similar ultimate loads and axial shortenings (Table 4). By contrast, the scatter of the results of the three oneply specimens is significantly larger (see Figure 10a and Table 4), suggesting that thinner FRP tubes might be more prone to local defects or local damage of the infill material. This is particularly evidenced by the curve of Specimen LHFFT-1-III, which experienced localized hoop rupture of FRP at a relatively early stage. Other than that, the effect of thickness of FRP tube is in general similar to FRP-confined normal concrete: when all other parameters are the same, a thicker FRP tube generally leads to a larger slope of the second-branch of the loadshortening curve as well as greater increases in strength and ductility.

\subsection{Axial Strain-Hoop Strain Behaviour}

The axial strain-hoop strain relationship has been well established to be the key parameter controlling the effectiveness of passive confinement (e.g. FRP confinement) on concrete [9]. In previous studies [36-38], the axial strains calculated by axial deformation of a mid-height region, typically of a height of 100-120 mm, were normally used. In the present study, two LVDTs were installed on the FRP tube of each specimen to measure the $100 \mathrm{~mm}$ mid-height deformation. However, the readings of the two LVDTs were found to be significantly affected by local damage of the resin matrix of FRP tube under large axial shortenings (e.g. up to $8.6 \%$ of the height), and thus do not always reflect the actual axial deformation of the infill LH material. Therefore, the nominal axial strains, which were taken as the average strains over the whole height of the specimen and were calculated using the overall axial shortenings, are used in the present study, unless otherwise specified. 
Figure 13 shows the axial strain-hoop strain curves of all the LHFFT specimens, in which the hoop strains were averaged from readings of the three hoop strain gauges outside the overlapping zone at the mid-height. For some specimens, one strain gauge was damaged during the loading process due to the local resin damage as discussed above. For these specimens, the average readings of the surviving strain gauges were used. The number of strain gauges used for calculating the average is also given in Table 4. As expected, at the same axial strain, the specimens confined by a thicker FRP tube generally had a lower hoop strain.

\subsection{Comparison between LHFFTs and HFFTs}

The axial load-shorting curves of the HFFT specimens are compared with those of the corresponding LHFFT specimens (i.e. two-ply specimens) in Figure 11. It is evident from Figure 11 that the curves of the HFFT specimens are significantly lower than the LHFFT specimens, although the load capacity of the unconfined high-water material cylinders (i.e. $28.6 \mathrm{kN}$ ) is slightly larger than that of the unconfined LH cylinders (i.e. $20.4 \mathrm{kN}$ ).

Figure 11 also shows that the ultimate axial shortenings of the HFFT specimens are much larger than (approximately three times) those of the LHFFT specimens. As both types of specimens failed by hoop rupture of FRP, the above observation implies that at the same axial strain, the lateral expansion of the HFFT specimens was much smaller than that of the LHFFT specimens. This is further supported by a comparison of the axial strain-hoop strain curves of the two groups of specimens (Figure 14), and is believed to be at least partially due to the fact that some water was squeezed out of the HFFT specimens during the tests. The loss of water in these specimens led to a reduction in volume of the infill material, and consequently reduced lateral expansion and reduced confining pressure at the same axial strain.

The test results presented above suggest that the use of coarse lumps/aggregates in the infill material is effective in enhancing the load capacity of the confined specimens, but at the same time it leads to reduction in the ultimate axial shortening. Taking this into consideration, the volume ratio of the coarse lumps may be taken as a design variable for different applications.

\subsection{Comparison between LHFFTs and LFFTs}

The axial load-shorting curves of the LFFT specimens are compared with those of the corresponding LHFFT specimens (i.e. two-ply specimens) in Figure 12. It is evident that the former are significantly lower than the latter. In addition, different from those of LHFFT and HFFT specimens, the curves of LFFT specimens show an approximately linear shape.

The initial stiffness of the LFFT specimens is also shown to be significantly smaller than that of the LHFFT specimens (Figure 12), due to the fact that the aggregates in the former did not take significant loads at the initial loading stage, because of the inner voids between them. In addition, the random distribution of the coarse aggregate had led to significantly non-uniform lateral expansion of the FRP tube. Such non-uniform lateral expansion, together with the early local damage of the resin matrix, led to a relatively low average hoop strain at the final failure of FRP tube. 
The comparison presented above suggest that the use of high-water material to fill the voids between random distributed coarse lumps/aggregates leads to enhanced stiffness and load capacity of the confined specimens. It, on the other hand, also verifies that LFFT specimens can have a significant load capacity and may be used as standing supports when binders are not readily available.

\section{COMPARISON WITH JIANG AND TENG'S (2007) MODEL}

\subsection{General}

It is evident from Figure 10 that the curves of all LHFFT specimens feature a bilinear shape, which is similar to that of FRP-confined normal concrete. In this section, the test results are compared with the predictions of Jiang and Teng's analysis-oriented model [39], which was proposed and has been widely accepted as an accurate model for FRP-confined normal concrete [39]. In making the predictions, all the curves are terminated at a point when the hoop strain reaches the maximum hoop rupture strain of three nominally identical specimens tested in each group. In addition, the equations used in Jiang and Teng's model [39] for the elastic modulus and axial strain at the peak stress of unconfined concrete were adopted, as these properties were not measured in the present study.

\subsection{Axial Strain-Hoop Strain Curves}

The predicted axial strain-hoop strain curves are plotted in Figure 15 to compare with the experimental curves. It is evident that Jiang and Teng's model [39] generally provides reasonably close predictions of the test results. The differences between the predicted and the experimental curves appear to be the largest for one-ply specimens, probably due to the rather non-uniform deformation of the specimens which was not captured by the limited number of discrete strain gauges.

\subsection{Axial Load-Axial Strain Curves}

In normal concrete columns confined by an FRP tube with only hoop fibres, the direct load contribution of the FRP tube is generally much smaller than that of the concrete and can thus be ignored. However, the load taken by FRP may not be ignored in LHFFT specimens due to the relatively low strength of the LH material. To examine this effect, two sets of predicted axial load-axial strain curves are plotted in Figure 16 to compare with the test results. In Figure 16, the curves labelled "Predicted curve - I" are obtained by the following way: (1) calculating the axial stress-axial strain curve of the confined LH material using Jiang and Teng's model [39]; (2) calculating the axial load-axial strain curve of the confined LH material using the cross-section area of the specimen; (3) for a given axial strain, calculating the axial load taken by the LHFFT specimen by adding the load taken by the FRP tube. In doing (3), it is assumed that: (a) the load taken by the FRP tube at a given strain is the same as that obtained in the hollow tube test at the same strain, before the latter reaches the peak load; (b) after that, the load taken by the FRP tube is assumed to be equal to the peak load from the hollow tube test. The use of the simplified second assumption is due to the difficulty in accurately accounting for the damage process of FRP tube in LHFFT specimens. The curves labelled "Predicted curve - II" in Figure 16 are obtained by following the above (1) and (2), and assuming that the direct load contribution of the FRP tube can be ignored. 
For two- and three-ply specimens, it is evident that the experimental curves generally lie between the two predicted curves: when the axial strain is relatively small (i.e. $<0.01$ ), the experimental curves appear to be close to "Predicted curve - I", but they become increasingly closer to "Predicted curve - II" with the increase of axial strain. The above observation suggests that Jiang and Teng's model [39] can generally provide reasonable predictions of the stress-strain behaviour of the confined LH material, and that the direct load contribution of FRP tube in LHFFT specimens can be significant at small axial strains but may become nearly zero at large deformation.

For one-ply specimens, the scatter of test results was larger than that of their two- or three-ply counterparts. The curve of Specimen LHFFT-1-I still appears to be lie between the two predicted curves, but the curves of Specimens LHFFT-1-II and III are seen to be slightly tube during the tests.

Given the above discussion, it is suggested that the FRP tube for practical applications should not be too thin. For design use, the directly contribution of FRP tube may be conservatively ignored when calculating the ultimate load of the LHFFT columns, but should generally be considered when calculating the initial stiffness of the columns.

\section{CONCLUSIONS}

This paper has presented the conceptual development of a new FRP tubular column with large deformation capacity. The new column consists of an outer FRP tube, and an infill made of coarse (waste) lumps as well as CSA-based cementitious material with high water content. Besides its large deformation capacity, the new column allows the extensive, direct and easy use of waste materials and eliminates the need for mixing concrete on site or transporting commercial concrete. Direct comparisons between the new column and two widely used standing supports in underground mines has also been made, which shows that it is a promising alternative to the existing technology.

This paper has also presented results from a series of compression tests to confirm the expected structural advantages of the new column, and to understand its structural mechanism and behaviour. The test results have also been compared with an analysisoriented model for FRP-confined normal concrete. The results and discussions presented in the paper allow the following conclusions to be drawn:

(1) The new column (i.e. LHFFT) possesses excellent structural performance including a continuously ascending load-strain curve with a very large ultimate axial shortening. The confinement provided by the FRP tube leads to significant enhancement in the ultimate load and deformation capacity of the LH material, and such enhancement increases with the thickness of the FRP tube.

(2) Compared with LFFTs, LHFFTs are superior in the load capacity and the initial stiffness. Compared with HFFTs, LHFFTs are superior in the load capacity but generally have a lower ultimate axial shortening if the same FRP tube is used. HFFTs may lose part of the water when subjected to large axial deformation.

(3) Jiang and Teng's model [39] can provide reasonably predictions of the behaviour of LHFFTs. 
It should be noted that the tests presented in this paper are only used to provide the first insight and to demonstrate some advantages of LHFFTs, and the parameters used in the tests should not be taken as typical for various applications. In practice, the behaviour of LHFFTs can be optimized by properly selecting the key parameters, including the type and thickness of FRP tube, the type and volume ratio of coarse lumps/aggregates and the water-to-powder ratio of the high-water material. For example, the nominal axial strain of the tested specimens deformation capacity is required. Similarly, the optimization of section configuration, as exemplified by those shown in Figure 2, is another aspect which deserves future research.

\section{ACKNOWLEDGMENTS}

The authors are grateful for the financial support provided by the Australian Government through the Australian Research Council's Discovery Projects funding scheme (project ID: DP170102992). The authors also wish to thank the University of Wollongong for the financial support for the second author's PhD study.

\section{REFERENCES}

[1] Han LH, Li W, Bjorhovde R. Developments and advanced applications of concrete-filled steel tubular (CFST) structures: Members. Journal of Constructional Steel Research. 2014;100:211-28.

[2] Shanmugam NE, Lakshmi B. State of the art report on steel-concrete composite columns. Journal of Constructional Steel Research. 2001;57:1041-80.

[3] Gupta P, Sarda S, Kumar M. Experimental and computational study of concrete filled steel tubular columns under axial loads. Journal of Constructional Steel Research. 2007;63:182-93.

[4] Patel VI, Hassanein M, Thai H-T, Al Abadi H, Paton-Cole V. Behaviour of axially loaded circular concrete-filled bimetallic stainless-carbon steel tubular short columns. Engineering Structures. 2017;147:583-97.

[5] Chen CC, Lin NJ. Analytical model for predicting axial capacity and behavior of concrete encased steel composite stub columns. Journal of Constructional Steel Research. 2006;62:424-33.

[6] Mirza S, Lacroix E. Comparative strength analyses of concrete-encased steel composite columns. Journal of Structural Engineering. 2004;130:1941-53.

[7] Teng JG, Chen JF, Smith ST, Lam L. Behaviour and strength of FRP-strengthened RC structures: a state-of-the-art review. Proceedings of the institution of civil engineers-structures and buildings. 2003;156:51-62.

[8] Hollaway LC, Teng JG. Strengthening and rehabilitation of civil infrastructures using fibrereinforced polymer (FRP) composites: Elsevier, 2008.

[9] Yu T, Teng JG. Design of concrete-filled FRP tubular columns: provisions in the Chinese technical code for infrastructure application of FRP composites. Journal of Composites for Construction. 2010;15:451-61.

[10] Mirmiran A, Shahawy M. A new concrete-filled hollow FRP composite column. Composites Part B: Engineering. 1996;27:263-8.

[11] Teng JG, Yu T, Wong YL, Dong SL. Hybrid FRP-concrete-steel tubular columns: concept and behavior. Construction and Building Materials. 2007;21:846-54.

[12] Yu T, Zhang SS, Huang L, Chan CC. Compressive behavior of hybrid double-skin tubular columns with a large rupture strain FRP tube. Composite Structures. 2017;171:10-8.

[13] Yu T, Teng JG, Wong YL. Stress-strain behavior of concrete in hybrid FRP-concrete-steel double-skin tubular columns. Journal of Structural Engineering. 2009;136:379-89.

[14] Zhang B, Teng JG, Yu T. Experimental behavior of hybrid FRP-concrete-steel double-skin tubular columns under combined axial compression and cyclic lateral loading. Engineering Structures. 2015;99:214-31.

[15] Barczak T. An overview of standing roof support practices and developments in the United States. Proceedings of the Third South African Rock Engineering Symposium. Johannesburg, Republic of South Africa: South African Institute of Mining and Metallurgy; 2005. p. 301-34. 
[16] Tarrant G. Loading mechanics of the 'Can'and implications for improved strength and stiffness properties. In: Aziz N, editor. Coal Operators' Conference. University of Wollongong \& the Australasian Institute of Mining and Metallurgy2005. p. 63-72.

[17] Tarrant G. New concepts in tailgate strata behaviour and implications for support design: University of New South Wales, 2006.

[18] Jia M, Bai JB, Tian T. Research on pier column gob-side entry retaining technology. Coal Science \& Technology. 2014;42:18-22.

[19] Jia M, Xu Y, Jiang XY, Bai JB. The gob-side entry retaining technology with pre-seting pier column. Journal of Mining \& Safety Engineering. 2017;34:228-34.

[20] Shook MT, Sindelar MF, Jiang H, Luo Y. Quantification of ventilation enhancement using the Eye CAN roof support. International Journal of Mining Science and Technology. 2017;27:153-8.

[21] Barczak TM. Research developments that contributed to the landscape of longwall roof support design over the past 25 years. In: Syd P, editor. Advances in Coal Mine Ground Control. 1 ed: Elsevier; 2017.

[22] Batchler T. Analysis of the design and performance characteristics of pumpable roof supports. International Journal of Mining Science and Technology. 2017;27:91-9.

[23] Barczak T, Tadolini S. Pumpable roof supports: an evolution in longwall roof support technology. Transactions-society for mining metallurgy and exploration incorporated. 2005;324:19-31.

[24] Zhou Q, Xu H, Liu J. Unstable failure characteristics and performance improvement of waterhigh filling materials. Journal of China Coal Society. 2017;42:1123-9.

[25] Sun CD, Zhang DS, Wang XF, Zhou R. Large-size test on creep characteristics of high water material for filling body beside roadway. Journal of Mining \& Safety Engineering. 2012;29:487-91.

[26] Feng GM, Ding Y, Zhu HJ, Bai JB. Experimental research on a superhigh-water packing material for mining and its micromorphology Journal of China University of Mining \& Technology. 2010;39:813-9.

[27] Wang XF, Zhang DS, Sun CD, Wang Y. Surface subsidence control during bag filling mining of super high-water content material in the Handan mining area. International Journal of Oil, Gas and Coal Technology. 2016;13:87-102.

[28] ASTM-D3039/D3039M. Standard test method for tensile properties of polymer matrix composite materials. West Conshohocken, PA: American Society for Testing and Materials; 2017.

[29] GB5350-2005-T. Fiber-reinforced thermosetting plastic composites pipe: determination for longitudinal compressive properties. China: The Standards Press of China; 2005.

[30] Song CY, Chen KP, Wang H. The Mechanism of hydration and hardening reaction of high-water material. Bulletin of Mineralogy, Petrology and Geochemistry. 1999;18:261-3.

[31] Sun HH, Qiu YX, Wu ZY, Wu J. Mine used high water bed solidification support material. China: Chinese Patent; 1990.

[32] ASTM-C191-13. Standard test methods for time of setting of hydraulic cement by vicat needle. West Conshohocken, PA: American Society for Testing and Materials; 2013.

[33] MT/T420-1995. High-water content backfilling material. China: State Administration of Work Safety; 1995.

[34] ASTM-C136/C136M. Standard test method for sieve analysis of fine and coarse aggregates. West Conshohocken, PA: American Society for Testing and Materials; 2014.

[35] ASTM-D7012-10. Standard test Method for compressive strength and elastic moduli of intact rock core specimens under varying states of stress and temperatures. West Conshohocken, PA: American Society for Testing and Materials; 2010.

[36] Ozbakkaloglu T, Lim JC, Vincent T. FRP-confined concrete in circular sections: Review and assessment of stress-strain models. Engineering Structures. 2013;49:1068-88.

[37] Yu T, Fang XL, Teng JG. FRP-confined self-compacting concrete under axial compression. Journal of materials in civil engineering. 2013;26:04014082.

[38] Wong YL, Yu T, Teng JG, Dong SL. Behavior of FRP-confined concrete in annular section columns. Composites Part B: Engineering. 2008;39:451-66.

[39] Jiang T, Teng JG. Analysis-oriented stress-strain models for FRP-confined concrete. Engineering Structures. 2007;29:2968-86. 